\title{
ELEKTRONİK DİZ PROTEZİ İÇİN YÜRÜYÜŞ HAREKET DENKLEMLERİNİN ÇÖZÜMLEMESİ VE ORANSAL TÜREVSEL DENETİM UYGULAMASI
}

\author{
Kurtuluş Erinç AKDOĞAN ${ }^{1}$, Atila YILMAZ ${ }^{2}$ \\ ${ }^{1}$ Proline Bilișim Sistemleri Ticaret A.S., Ankara \\ ${ }^{2}$ Hacettepe Üniversitesi, Mühendislik Fakültesi, Elektrik ve Elektronik Mühendisliği Bölümü, Ankara \\ kurtuluserinc@gmail.com, ayilmaz@hacettepe.edu.tr
}

(Geliş/Received: 03.03.2015; Kabul/Accepted: 22.10.2015)

ÖZET

\begin{abstract}
$\mathrm{Bu}$ çalışmada, elektronik dizüstü protezi (EDP) için gerekli denetim yöntemlerinin geliştirilebileceği bir benzetim tabanlı geliştirim ortamı (BTGO) tasarlanmıştır. Bu amaçla mevcut yürüyüş hareket denklemleri, robot kolları esas alınarak türetilmekte ve doğrulukları, rapor edilen gerçek yürüyüş verileri ile ileri çözüm yapılarak sınanmaktadır. İleri çözüm benzetimleri, incelenen yürüyüş hareket denklemlerinin, yürüyüşün salınım evresini tanımlayabildiğini ancak duruş evresinde yer tepki kuvvetinin hesaba katılmadığını göstermiştir. Eklem torklarının doğuracağı ilgili eklem açılarının bulunması için yürüyüş hareketi denkleminin ters çözümü sayısal olarak gerçekleştirilmiştir. Ters çözüm kullanılarak BTGO'da uygulama yapmak amacıyla oransal türevsel (OT) denetim, örnek bir denetim yöntemi olarak seçilmiş ve incelenmiştir. Diz sisteminin girişi olan tork ve çıkışı olan açı arasındaki doğrusal olmayan ilişsi doğrusallaştııılarak, bir transfer fonksiyonu oluşturulmuştur. OT denetleyici ve bu transfer fonksiyonu kullanılarak denetimli bir diz eklemi sistemi oluşturulmuştur. OT denetleyicinin oransal ve türevsel kazançları kök yer yöntemi ile belirlenmiştir. Gerçek diz açıları, hedef değer olarak girildiğinde, sistemin ürettiği diz açısının hedef değerleri takip edebildiği gözlenmiştir. Tasarlanan BTGO, EDP için gereken denetim yöntemlerinin incelenmesini kolaylaştırmaktadır.
\end{abstract}

Anahtar Kelimeler: Elektronik diz üstü protezi, yürüyüş hareketi denklemi, oransal türevsel denetim, ters çözüm

\section{ANALYSIS OF GAIT MOTION EQUATIONS AND APPLICATION OF PROPORTIONAL DERIVATIVE CONTROL FOR ELECTRONIC ABOVE KNEE PROSTHESIS}

\begin{abstract}
In this study, a simulation based development environment (SBDE) is designed to develop control methods required for electronic above knee prosthesis (EAP). For this purpose existing gait motion equations are derived on the basis of robot arm and their accuracy are tested by performing forward solution with real gait data reported in the literature. Forward solution simulations show that analyzed gait motion equations can describe swing phase but in stance phase, ground reaction force is not involved in calculations. Inverse solution of gait motion equations has been implemented numerically to determine joint angles caused by corresponding joint torques. In order to make an application in SBDE using inverse solution, proportional derivative (PD) control has been selected as an example control method and analyzed. A transfer function is formed by linearizing the nonlinear relationship between torque and angle as input and output of knee system. A controlled knee joint system is set up by employing this transfer function and PD controller. Proportional and derivative gains of PD controller is determined by using root locus method. Substituting real knee angles as target values, it is observed that knee angles produced by system can follow the target values. Designed SBDE facilitates analysis of control algorithms required for EAP.
\end{abstract}

Keywords: Electronic above knee prosthesis, equation of gait motion, proportional derivative control, inverse solution 


\section{GÍRISŞ (INTRODUCTION)}

Uzuv kayıplarında ikinci sırada bulunan diz eklemi kayıpları [1], bacağını diz üstünden kaybeden kişinin hareket kabiliyetini önemli ölçüde sınırlandırması nedeniyle kişinin günlük hayatını diğer uzuv kayıplarına göre daha fazla etkilemektedir. İdeal bir diz üstü protezin amacı çevresel koşullara ve kullanıcının isteklerine uyum göstererek doğal hareket kabiliyetini geri kazandırmak olarak tanımlanmaktadır [2]. Ancak diz ekleminin vücudun en büyük ve yapı olarak en karmaşık eklemi [3] olmasından dolayı henüz diz ekleminin tüm işlevlerini yerine koyabilecek bir diz üstü protez geliştirilmemiştir.

Mevcut protezlerin çoğu, sürtünme, yaylanma ve sönümleme katsayıları gibi sabit mekanik özellikli edilgen bir mekanizmaya sahiptir [4]. Edilgen protezler, kullanımdan önce yapılan sabit ayarlara göre yürüyüşün salınım evresi için kalçadan kaynaklanan hareketi bahsedilen bir sabit katsayıya göre sönümlendirmektedir. Dolayısıyla kullanıcı önceden ayarlanmış tek bir hızda yürüyebilmektedir. Farklı hızda yürüyebilme gibi doğal yürüyüşe yakın bir yürüyüş için değiştirgelerini kullanıcı isteklerine ve çevresel koşulların değişimine göre ayarlayabilen EDP araştırmaları, 1970'lerde başlamıştır [5]. Bu diz protezleri sahip olduğu elektronik donanımla, kullanıcısının isteklerini ve çevresel koşulları algilayarak ve hareketlendiricisini denetleyerek, diz eklemini hedef hareket örüntüsüne yaklaştırmaktadır [5-9]. Duyarga, hareketlendirici ve denetim yöntemi bir EDP'nin başarımını belirleyen üç temel bileşendir. $\mathrm{Bu}$ çalışmada bir EDP için gereken denetim yöntemlerinin geliştirilebileceği ve sınanabileceği bir benzetim tabanlı geliştirim ortamı tasarlanmıştır.

Yürüyüş hareketi bacakta yer alan kasların denetimli olarak ürettiği kuvvet ve tork sonucu oluşmaktadır. Dizin yürüyüş esnasında hedef bir açıya ulaşabilmesi için eklemlerden belirli miktarda torkun üretilmesi gerekmektedir. Önceki çalışmalarımızda geliştirilen hareket inceleme düzenekleri kullanılarak sağlıklı bir insanın yürüyüşünde oluşan evreler, bağlantı ve eklem açıları gözlemlenmiştir [10-12]. Ancak yürüyüşün tam olarak anlaşılabilmesi için yürüyüşün kinematik verilerinin oluşmasını sağlayan fakat ölçülemeyen eklem torklarının belirlenmesi gerekmektedir. Böylelikle yürüyüş, girişi eklem torkları, çıkışı ise kinematik değişkenler olan bir sistem olarak ifade edilebilir. Bu amaçla Kim ve Oh'nun [13] kullandığ yürüyüş hareket denklemi, bacağın indirgendiği iki bağlantılı bir düzlemsel robot kolundan yola çıkılarak türetilmekte ve doğruluğu incelenmektedir. Bundan sonraki aşamada, Winter'ın [14] ölçtüğü gerçek yürüyüş bilgileri kullanılarak, türetilen yürüyüş denkleminin ileri çözümü yapılmaktadır. Denklemin ileri çözümünde, eklem açılarına ve diğer kinematik değişkenlere karşılık hesaplanan eklem tork değerleri ile Winter'ın hesapladığı tork değerleri [14] karşılaştırılmaktadır. Buradan elde edilecek sonuç, Kim ve Oh'nun [13] modelinin başarımı ve uygulanabilirliği hakkında bilgi vermektedir.

Yürüyüş hareket denklemleri, robot kolunun hareket denklemlerinde olduğu gibi, eklemlerde oluşturulan tork sonucu elde edilen eklem açılarının hesaplanmasında kullanılmaktadır. Denklemlerin ters çözümü anlamına gelen bu uygulama, bu çalışmada MATLAB ortamında sayısal olarak gerçekleştirilmektedir. Son aşamada ise kalçanın sağlıklı ve tüm verilerinin bilindiği, diz eklemi yerine ise EDP'nin kullanıldığı varsayılarak ve Kim ve Oh'nun yürüyüş hareket denklemleri kullanılarak, girişi tork, çıkışı diz açısı olan bir hareketlendirici tanımlanmaktadır. $\mathrm{Bu}$ hareketlendiricinin giriş-çıkış ilişkisinin doğrusallaştırılarak bir transfer fonksiyonu elde edilmesiyle denetim yöntemlerinin uygulanabileceği BTGO oluşturulmuş bulunmaktadır. EDP'ye yönelik bir denetim yöntemini, tasarlanan BTGO'da incelemek amaciyla temel bir denetim yöntemi olan ve basit yapıya sahip OT denetleyicili bir EDP sistemi kurgulanmıştır. OT denetleyicinin kazanç değerleri kök yer (root locus) yöntemi ile ayarlandıktan sonra Winter'ın ölçtüğü hedef diz açıları sisteme giriş olarak uygulanmakta ve sistemin çıkışından elde edilen diz açısı hedef değerlerle karşılaştırılmaktadır. Oluşturulan BTGO, OT denetleyicinin yanı sıra diğer denetim yöntemlerinin uygulanabilme ve ilgili yöntemin parametrelerinin incelenebilme kolaylığı sağlamaktadır.

\section{YÜRÜYÜSS HAREKETININ DENKLEMI (EQUATION OF GAIT MOTION)}

$\mathrm{Bu}$ bölümde, bacak ve kol modeli arasındaki yapısal benzerlik kullanılarak, Kim ve Oh'nun kullandığ1 yürüyüşün hareket denklemleri [13], robot kolun mevcut hareket denklemlerinden [15] türetilmektedir. Şekil 1a'da iki döner eklem ve bağlantıdan oluşan düzlemsel robot kolu gösterilmektedir. Şekil b'de ise insan bacağının bağlantı-parça modeli gösterilmektedir. Bacağın kalça ve diz eklemleri, robot koldaki döner eklemlere, uyluk ve baldır ise döner eklemler arasındaki bağlantılara indirgenerek robot kol için üretilen hareket denklemleri, yürüyüș hareket denklemlerine dönüştürülmektedir. Her iki modelde de bağlantı sayısı $i=2$ olmak üzere, bağlantıların, uzunlukları $l_{i}$; ağırlıkları, $m_{i}$; eylemsizlik momentleri, $I_{i}$; merkezlerinin eklemlere uzaklıkları, $a_{i}$ ile gösterilmektedir. Robot kolun eklem açıları, $q_{i}$, bacağın eklem açıları, $\theta_{i}$ ile tanımlanmaktadır. Robot kolun eklemlerinden uygulanan torklar, $\tau_{i}$ ile gösterilirken bacağın kalça torku $u_{k}$, diz torku ise $u_{d}$ ile gösterilmektedir. Bacak modelinde, robot kol modelindeki sabitlenmiş ilk eklemden farklı olarak, kalça eklemi sabitlenmemiştir ve $x, y$ kartezyen eksenlerindeki hareketi, $x_{k}$ ve $y_{k}$ ile gösterilmektedir. 


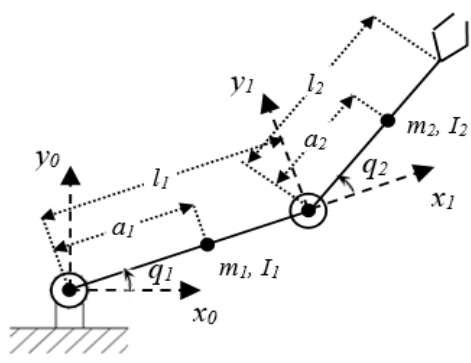

a)

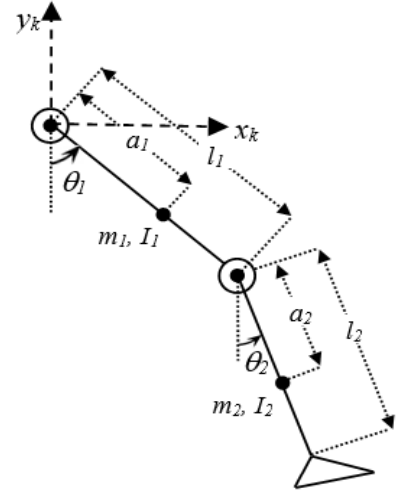

b)

Şekil 1. a) İki döner ekleme sahip bir robot kolu [15] ; b) İnsan bacağının bağlantı parça modeli [13]. ( a) A robot arm having two revolute joints [15]; b) Link segment model of leg [13]).

Robot kolun eklemlerinin hareketi sonucu, ikinci bağlantının ucunun konumunu gösteren ileri kinematik denklemlerini oluşturmak üzere DenavitHartenberg (DH) gösterimini kullanarak dayanak çerçeveler ve dönüşüm dizeyleri belirlenmektedir [15]. Şekil 1a'da, DH gösterimine göre belirlenen dayanak $x_{0} y_{0}$ ve $x_{I} y_{1}$ çerçeveleri gösterilmektedir. Robot kolun ucunun konumundan bağlantı açlarının hesapladığı ters kinematik çözüm, ileri kinematik çözüme göre daha karmaşı sorundur. Bu çözüm için basit olması nedeniyle geometrik çözüm tercih edilmektedir. Elde edilen kinematik denklemler kullanılarak, eklemlerin hizı ile robot kolun ucunun hızı arasındaki hız ilişkisi açıklanabilir. Şekil 1a'da tanımlanan dayanak çerçeveler ve kinematik ilişkiden bir Jacobian dizeyi elde edilerek, eklem ve bağlantılar arasındaki hı kinematiği türetilmektedir [15]. Jacobian dizeyi, eklemlerdeki tork ve hareket arasındaki ilişkiyi açıklamak üzere dinamik denklemlerin hesaplanmasında kullanılmaktadır.

Robot kolun hareket denklemlerinin türetilmesine, sistemin Lagrangian'ının $(L), \quad$ sistemin kinetik enerjisinden potansiyel enerjinin çıkartılarak elde edilmesi ile devam edilmektedir. L'yi kullanarak, (1) ile gösterilen Euler-Lagrange (EL) denklemleri türetilmektedir [15]. Dizey biçiminde gösterilen (1) eşitliğinin, dizey elemanları cinsinden yazılmış hali (2) ile gösterilmektedir [15]. Bu denklem, robot kolunun eklemlerinden uygulanan torklar, $\tau_{k}$, ile eklem açıları, $q_{k}$, arasındaki ilişkiyi ifade etmektedir ve yürüyüş hareket modelinin de temelini oluşturmaktadır. Her bir bağlantı için kinematik çözümden elde edilen çizgisel ve açısal Jacobian dizeyleri, $J_{v i}$ ve $J_{w i}$, ilgili bağlantının kütlesi, $m_{i}$, eylemsizlik gereyi (inertia tensor), $I_{i}$ kullanılarak (3) ile tanımlanan eylemsizlik dizeyi, $D$ hesaplanmaktadır. Her bir bağlantı için tanımlanan dönme dizeyi, $R_{i}$, ilgili bağlantının uç noktasının, $x_{0} y_{0}$ sabit çerçevesine göre konumunu tanımlamaktadır. (1) eşitliğinde gösterilen $C$ dizeyi, Christoffel sembolleri olarak adlandırılmaktadır ve dizey elemanları, (4) ile hesaplanmaktadır. (2) eşitliğindeki Christoffel sembollerini içeren terimin, $i=j$ durumunda oluşan $\dot{q}_{i}^{2}$ içeren bileşeni merkezkaç, $i \neq j$ durumunda oluşan $\dot{q}_{i} \dot{q}_{j}$ terimini içeren bileşenleri ise Coriolis olarak adlandırılmaktadır. (5) eşitliğinde, ilgili bağlantı için, $g_{k}$ bileşeni, bağlantının potansiyel enerjisi P'nin, bağlantı değişkenine göre türevinin alınması ile hesaplanmaktadır.

$$
\begin{aligned}
& D(q) \ddot{q}_{j}+C(q, \dot{q}) \dot{q}+g(q)=\tau \\
& \sum_{j=1}^{2} d_{k j}(q) \ddot{q}_{j}+\sum_{i=1}^{2} \sum_{j=1}^{2} c_{i j k}(q) \dot{q}_{i} \dot{q}_{j}+g_{k}(q)=\tau_{k}, k=1,2 \\
& D(q)=\sum_{i=1}^{n}\left\{m_{i} J_{v i}(q)^{T} J_{v i}(q)+J_{w i}(q)^{T} R_{i}(q) I_{i} R_{i}(q)^{T} J_{w i}(q)\right\} \\
& c_{i j k}=\sum_{i, j}\left\{\frac{\partial d_{k j}}{\partial q_{i}}+\frac{\partial d_{k i}}{\partial q_{j}}-\frac{\partial d_{i j}}{\partial q_{k}}\right\} \\
& g_{k}=\frac{\partial P}{\partial q_{k}}
\end{aligned}
$$

Türetilen denklemlere, robot kolun, $q_{1}$ ve $q_{2}$, eklem değişkenlerinin yerine, bu değişkenlerin kalça açısı $\theta_{l}$ ve diz açısı $\theta_{2}$ cinsinden karşılıkları yerleştirildiğinde bacak hareket denklemleri elde edilebilmektedir. Bacak ve kol değişkenlerinin ve bu değişkenlerin birinci dereceden türevlerinin arasındaki ilişki, (6) (9) ile gösterilmektedir.

$$
\begin{aligned}
& \theta_{1}-\pi / 2=q_{1} \\
& \theta_{2}-\theta_{1}=q_{2} \\
& \dot{\theta}_{1}=\dot{q}_{1} \\
& \dot{\theta}_{2}-\dot{\theta}_{1}=\dot{q}_{2}
\end{aligned}
$$

Değişken dönüşümü yapılarak, (1) ile tanımlanan hareket denklemi, Kim ve Oh'nun kullandığı, (10) ile 
gösterilen hareket denklemine dönüştürülmektedir. Dönüşüme, dinamik denklemlerde kullanılan Jacobian dizeyinden başlanmaktadır. Dönüştürülen Jacobian dizeyi, (3) eşitliğinde yerine koyulduğunda (12) eşitliğindeki $D$ dizeyi elde edilmektedir. $D$ dizeyi kullanılarak, (4) eşitliğinde tanımlanan Christoffel sembolleri yeniden düzenlendiğinde, (13) eşitliğinde gösterilen $C$ dizeyi elde edilebilmektedir. Geriye türetilmesi gereken $g$ dizeyi kalmaktadır. (14) ile gösterilen bu dizey, yerçekimi ivmesinin yanı sıra kalçanın temel çerçevesinin $x$ ve $y$ ekseni yönündeki ivmelenmesini de içerdiğinden (5) ile tanımlanan $g$ dizeyinden farklıdır. Bu ivmelenmeler, potansiyel enerji hesaplanmasına katıldığında (14) elde edilmektedir. Sonuç olarak, bu bölümde yapılan incelemelerle, Kim ve Oh'nun önerdiği yürüyüş denklemleri [13], türetilmiş ve doğrulanmıştır.

$$
\begin{aligned}
& D(\theta) \ddot{\theta}+C(\theta, \dot{\theta}) \dot{\theta}+g(\theta)=\tau, \theta=\left[\begin{array}{l}
\theta_{1} \\
\theta_{2}
\end{array}\right] \\
& {\left[\begin{array}{ll}
D_{11} & D_{12} \\
D_{21} & D_{22}
\end{array}\right]\left[\begin{array}{l}
\ddot{\theta}_{1} \\
\ddot{\theta}_{2}
\end{array}\right]+\left[\begin{array}{l}
C_{1} \\
C_{2}
\end{array}\right]+\left[\begin{array}{c}
K_{1} \\
K_{2}
\end{array}\right]=\left[\begin{array}{cc}
1 & -1 \\
0 & 1
\end{array}\right]\left[\begin{array}{l}
u_{h} \\
u_{k}
\end{array}\right]} \\
& D(\theta)=\left[\begin{array}{cc}
I_{1}+m_{1} a_{1}^{2}+m_{2} l_{1}^{2} & m_{2} l_{1} a_{2} \cos \left(\theta_{1}-\theta_{2}\right) \\
m_{2} l_{1} a_{2} \cos \left(\theta_{1}-\theta_{2}\right) & I_{2}+m_{2} a_{2}^{2}
\end{array}\right] \\
& C(\theta, \dot{\theta})=\left[\begin{array}{c}
m_{2} l_{1} a_{2} \sin \left(\theta_{1}-\theta_{2}\right) \dot{\theta}_{2}^{2} \\
-m_{2} l_{1} a_{2} \sin \left(\theta_{1}-\theta_{2}\right) \dot{\theta}_{1}^{2}
\end{array}\right] \\
& g(\theta)=\left[\begin{array}{c}
\left(m_{1} a_{1}+m_{2} l_{1}\right)\left(\cos \left(\theta_{1}\right) \ddot{x}_{k}+\sin \left(\theta_{1}\right) \ddot{y}_{k}+\sin \left(\theta_{1}\right) g\right) \\
\left(m_{2} a_{2}\right)\left(\cos \left(\theta_{2}\right) \ddot{x}_{k}+\sin \left(\theta_{2}\right) \ddot{y}_{k}+\sin \left(\theta_{2}\right) g\right)
\end{array}\right]
\end{aligned}
$$

\section{DENKLEMLERIN GERÇEK YÜRÜYÜŞ VERILERI ILE SINANMASI (TESTING EQUATIONS WITH REAL GAIT DATA)}

Kim ve Oh'nun yürüyüş hareket modeli ile kinematik verilerin oluşmasını sağlayan eklem torkları hesaplanabilmektedir. Bu bölümde, Kim ve Oh'nun yürüyüş hareket denkleminin doğruluğu, gerçek bir yürüyüş verisi ile sınanmaktadır. Sınama, ileri ve ters

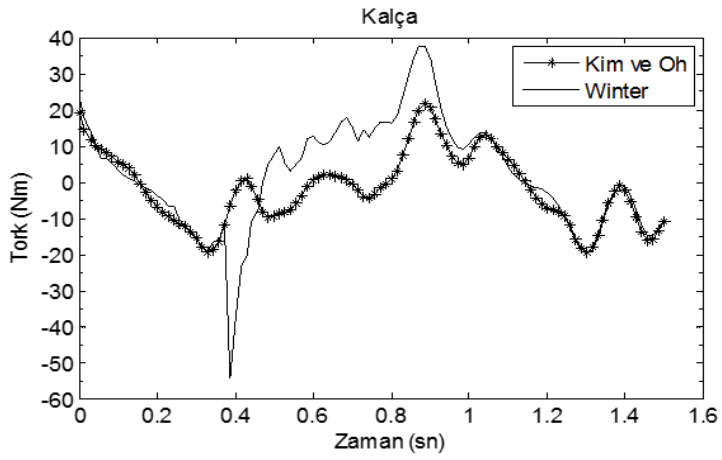

a) çözüm olmak üzere iki yolla yapılabilir. İleri çözümde, görüntü tabanlı hareket ölçüm düzeneklerinden ölçülen kinematik verilerden (11) eşitliğinin solunda yer alan açı, açısal hız ve ivme bilgileri denkleme yerleştirilerek, bu verilere karşılık oluşan torklar hesaplanmaktadır. Ters çözümde ise denkleme eklem torkları girilerek, denklemin sol tarafinda yer alan açı bilgileri elde edilmektedir. Yürüyüş verisi olarak Winter'ın [14], kütlesi $m=56,7 \mathrm{~kg}$, uyluk ve baldır ağırlığ $1, m_{l}=5,67 \mathrm{~kg}$ ve $m_{2}=3,46 \mathrm{~kg}$, uyluk ve baldır ağırlık merkezlerinin eklemlere uzaklıkları, $a_{1}=0,14 \mathrm{~m}$ ve $a_{2}=0,26 \mathrm{~m}$, uyluk ve baldırın eylemsizlik momentleri $I_{l}=0,0583 \mathrm{kgm} / \mathrm{sn}^{2}$ ve $I_{2}=0,057 \mathrm{kgm} / \mathrm{sn}^{2}$ olan bir kişinin, $6,2 \mathrm{~km} / \mathrm{sa}$ hızla yürürken, 69,9 çerçeve sıklığına sahip bir görüntü tabanlı hareket ölçüm sistemi ile ölçtüğü veriler kullanılmaktadır. Yerçekimi ivmesi $g=9,8 \mathrm{~m} / \mathrm{sn}^{21}$ dir.

\section{1 İleri Çözüm (Forward Solution)}

Winter'ın ölçtüğü kinematik veriler ve deneğin fiziksel özellikleri, (10) eşitliğinde yerlerine koyulduğunda hesaplanan ve aynı veriler için Winter'ın hesapladığı kalça ve diz torkları [14], Şekil $2 \mathrm{a}$ ve Şekil 2b'de gösterilmektedir. Yürüyüşün salınım evresi, deneğin sağ ayağının parmak ucunun, $t=0 \mathrm{sn}$ anında yerden kesildiği ve deneğin sağ topuğunun yere temas ettiği $t=0,386$ sn'ye kadar sürmektedir. Duruş evresi ise $t=0,386 \mathrm{sn}$ 'den, ayağın parmak ucunun yerden kesildiği $t=0,987$ sn'ye kadar sürmektedir. $t=1,373$ sn'de topuk yere tekrar temas etmektedir. Winter'ın hesapladığı ile Kim ve Oh'nun yürüyüş denklemlerinden hesaplanan torklar, yürüyüşün salınım evresi için uyuştuğu, Şekil $2 \mathrm{a}$ ve Şekil 2b'den görülebilmektedir. Ancak duruş evresinde, her iki eklem için hesaplanan tork verileri birbirinden farklıdır. Bu farkın sebebi, Kim ve Oh'nun yürüyüş hareketi denklemlerinin, yürüyüşün duruş evresinde oluşan yer tepki kuvvetini, robot kolunun hareket denklemlerinde olduğu gibi, hesaba katmamasından kaynaklanmaktadır. EDP'nin başlıca amac1, salınım evresinde denetim yapılması olduğundan Kim ve Oh'nun modelinin, protezde kullanılacak olası bir denetim yöntemi için yeterli olacaktır. Ancak ayağın yerle temas ettiği bir hareket türünde bu model yeterli olmayacaktır.

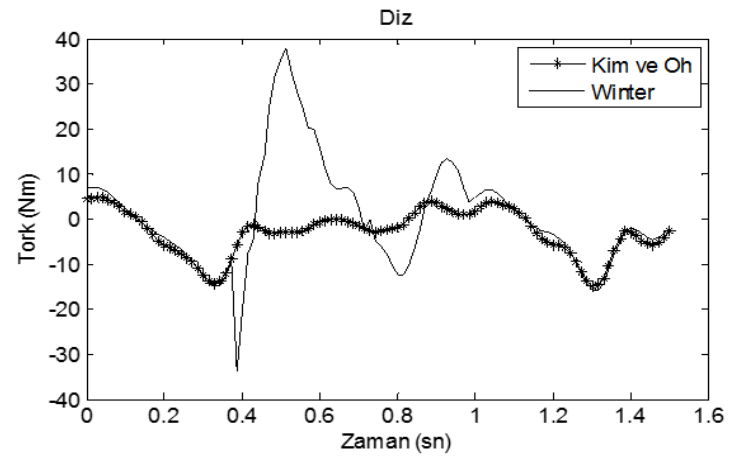

b)

Şekil 2. Kim ve Oh'nun kullandığı yürüyüş denkleminin ileri çözümünden elde edilen (*) ve Winter'ın hesapladığı torklar (-) [14]. a) Kalça eklemi; b) Diz eklemi. (Torques obtained from forward solution of gait equations employed by Kim and $\mathrm{Oh}(*)$ and the ones calculated by Winter (-). a) Hip joint; b) Knee joint.) 


\subsection{Ters Çözüm (Inverse Solution)}

Bacağın modellendiği iki eklemli yapıya dışarıdan bir bozunum (disturbance) etki etmediği varsayılırsa ve deneğe ait fiziksel özellikler değiştirilmeden kullanılırsa, (11) eşitliğinin ileri çözümünden hesaplanan torklarla, (11) eşitliğini tersten çözerek, ileri çözümde kullanılan eklem açıları hesaplanabilir. Bacağın hareket denklemlerinin tersten çözümü, eklem torklarını denetleyerek, hedef eklem açılarına ulaşmayı amaçlayan denetim yöntemlerini uygulamak üzere temel oluşturmaktadır. Ancak ters çözümde, hedef değerler için gereken torklar bilindiği için bir denetim mekanizmasına gerek yoktur.

İki bağlaşımlı doğrusal olmayan bayağı diferansiyel denklem olan (11), MATLAB programının RungeKutta yöntemini kullanan Ode45 çözücüsü ile sayısal olarak çözülmektedir. Ode45 çözücüsü sadece birinci dereceden diferansiyel denklemleri kabul etmektedir. Birinci dereceden yüksek diferansiyel denklemleri çözdürmek için her bir denklem, birinci dereceden diferansiyel denklemler olarak ifade edilmektedir. Bu nedenle (11) ile gösterilen denklemler, birinci dereceden diferansiyel denklemler şeklinde (15) ile gösterilen değişken değiştirmelerle yeniden düzenlenmiştir. Elde edilen birinci dereceden diferansiyel denklemler, sırasıyla (16), (17), (18) ve (19) ile gösterilmektedir.

$$
\begin{aligned}
& x(1)=\dot{\theta}_{1}, x(2)=\dot{\theta}_{2}, x(3)=\theta_{1}-\theta_{2}, x(4)=\theta_{2} \\
& d x 1=\left(\left(0.5324 \cos (x(3))\left(u_{k}-u_{d}\right)-u_{d}\right)-\right. \\
& \sin (x(3))\left(x(2)^{2} 0.3241+0.1745 \cos (x(3)) x(1)^{2}\right)- \\
& 0.9885 \cos (x(3))\left(\ddot{x}_{k} \cos (x(3)+x(4))+\right. \\
& \left.\ddot{y}_{k} \sin (x(3)+x(4))+g \sin (x(3)+x(4))\right)+ \\
& 1.032\left(\left(\cos (x(4)) \ddot{x}_{k}+\sin (x(4))\right) \ddot{y}_{k}+\right. \\
& \sin (x(4)) g)) /\left(0.1725 \cos (x(3))^{2}-0.7609\right)
\end{aligned}
$$

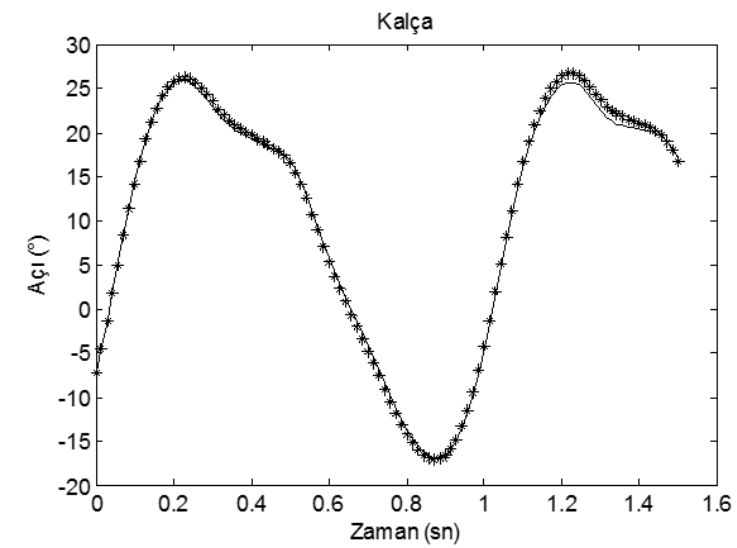

a)

$$
\begin{aligned}
& d x 2=\left(\left(-u_{k}+u_{d}(1+0.4259 \cos (x(3)))\right)+\right. \\
& \sin (x(3))\left(x(1)^{2} 0.3241+0.1380 \cos (x(3)) x(2)^{2}\right)+ \\
& 1.8569\left(\left(\cos (x(3)+x(4)) \ddot{x}_{k}\right)+\sin (x(3)+\right. \\
& \left.x(4)) \ddot{y}_{k}+\sin (x(3)+x(4)) g\right)- \\
& 0.4396 \cos (x(3))\left(\cos (x(4)) \ddot{x}_{k}+\sin (x(4)) \ddot{y}_{k}+\right. \\
& \sin (x(4)) g)) /\left(0.1380 \cos (x(3))^{2}-0.6088\right) \\
& d x 3=x(2)-x(1) \\
& d x 4=x(1)
\end{aligned}
$$

Hareket denklemi tersten çözülerek, bir önceki bölümde elde edilen eklem tork değerlerinden kalça ve diz açıları hesaplanmaktadır. Ancak ode45'e sağlanan kalça ve diz torkları, (15)-(19) ile gösterilen diferansiyel denklemlerin, Kim ve Oh'nun yürüyüş denkleminden türetilmiş olması nedeniyle Winter'ın hesapladığı tork verileri yerine, Kim ve Oh'nun yürüyüş denklemlerinden elde edilen tork değerleridir. Bu denklemlerin sayısal çözümü için 106 örnek uzunluğundaki, kalça ve diz torkları, kalça ekleminin $x$ ve $y$ eksenleri yönündeki çizgisel ivmeleri [14], (15) ile gösterilen değişkenlerin ilk değerleri ve son olarak ilgili 106 örneğin örneklenme zamanları [14], ode45'e sağlanmaktadır. Sayısal çözüm sonucu, (15) ile gösterilen değişkenler için ilk değerleri dışında kalan 105 örnek için hesaplama yapılmaktadır. İleri çözümde yapıldığı gibi hesaplamaların doğruluğunu sınamak için Winter'ın $6,2 \mathrm{~km} / \mathrm{sa}$ hızla yürüyen denekten ölçtüğü kalça ve diz eklemi açıları [14], dayanak olarak kullanılmıştır. Geliştirilen nümerik yoldan çözümün bulduğu eklem açıları ve Winter'ın görüntü tabanlı düzenekten ölçmüş olduğu dayanak eklem verileri karşılaştırılmak üzere Şekil 3a ve Şekil 3b'de bir arada gösterilmiştir. Sonuçlar, ileri çözümden elde edilen torklar kullanıldığı sürece, yürüyüş denkleminin sayısal

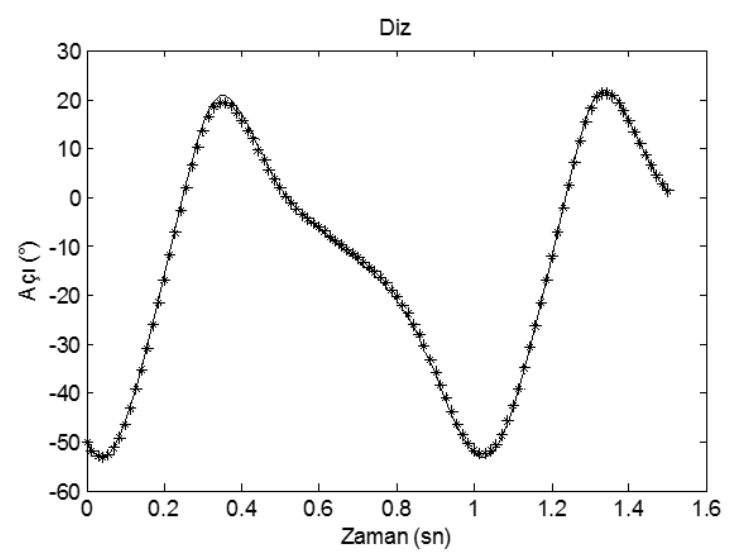

b)

Şekil 3. Ters çözüm (-) ile hesaplanan ve hedef (*) a) Kalça açısı; b) Diz açısı ( a) Hip angle; b) Knee angle calculated using inverse solution $(-)$ and target $\left({ }^{*}\right)$ ) 
yoldan ters çözümü ile eklem açılarının doğru hesaplanabileceğini göstermektedir. İdeal durumda, eğer EDP'ye, ilgili protezli bacağa ait hareket denklemi oluşturularak doğru tork değeri sağlanırsa, diz ekleminin hareketi denetimsiz olarak oluşturulabilir. Yürüyüş hareketinin ters çözümü, eklem torklarının bilinmediği durumda kullanılması gereken denetim yordamlarının geliştirilmesi için taban oluşturmaktadır. Bunun yanı sıra yapılan ileri ve ters çözüm incelemeleri, bacak hareketinin daha iyi anlaşılmasını sağlamıştır.

\section{ORANSAL TÜREVSEL (OT) DENETLIYYICI ÍLE Dİ DENETIMI (KNEE CONTROL WITH PROPORTIONAL DERIVATIVE (PD) CONTROLLER)}

Bu bölümde EDP'nin hareketinin denetlemesi üzerine benzetim yapmak için en temel denetim yöntemlerinden biri olan oransal türevsel denetleyici uygulanmaktadır. Bir geri beslemeli döngü denetim mekanizması olan OT denetleyici, sanayi uygulamalarında yaygın olarak kullanılan ve basit bir yapısı olan denetim yöntemidir. Temel bir yöntem olması nedeniyle, diz protezi için çeşitli denetimi yöntemlerinin incelenmesinde dayanak olabilecek sonuçlar ortaya koyacaktır.
4.1 Denklemin Doğrusallaştırılması (Linearization of Equation)

EDP'de kullanılacak hareketlendiricinin yapısı basite indirgenerek, girişi tork, çıkışı diz açısı olan bir hareketlendirici kullanıldığı varsayılmaktadır. Bu sistemin OT denetleyici ile denetlenmek istendiğinde oluşacak geri beslemeli sistem, Şekil 4'te gösterilmektedir. Blok diyagramdaki diz eklemi transfer fonksiyonu, diz torku ve diz açısı arasındaki ilişkiyi tanımlanmaktadır. (11) eşitliğinden elde edilen ve (20) ile gösterilen bu iki değiştirge arasındaki ilişki doğrusal olmadığından aralarında bir transfer fonksiyonu oluşturabilmek için (20) eşitliğinin doğrusallaştırılması gerekmektedir. $\mathrm{Bu}$ amaçla, (21) ile gösterildiği gibi $u_{d}$, diz torkundan, (20) eşitliğindeki diz açısının ikinci dereceden türevini, $\ddot{\theta}_{2}$, içeren terim dışındaki doğrusallığı bozan tüm terimler, çıkarılmıştır. Çıkarılan terimler, Şekil 4'te gürültü olarak gösterilen ve (22) eşitliğinde, $d$, olarak ifade edilen değişkenin altında toplanmıştır. Sonuçta elde edilen transfer fonksiyonu (23) ile gösterilmektedir. Bu transfer fonksiyona göre yeniden düzenlenen OT denetleyicili diz sisteminin blok diyagramı Şekil 5 'te gösterilmektedir.

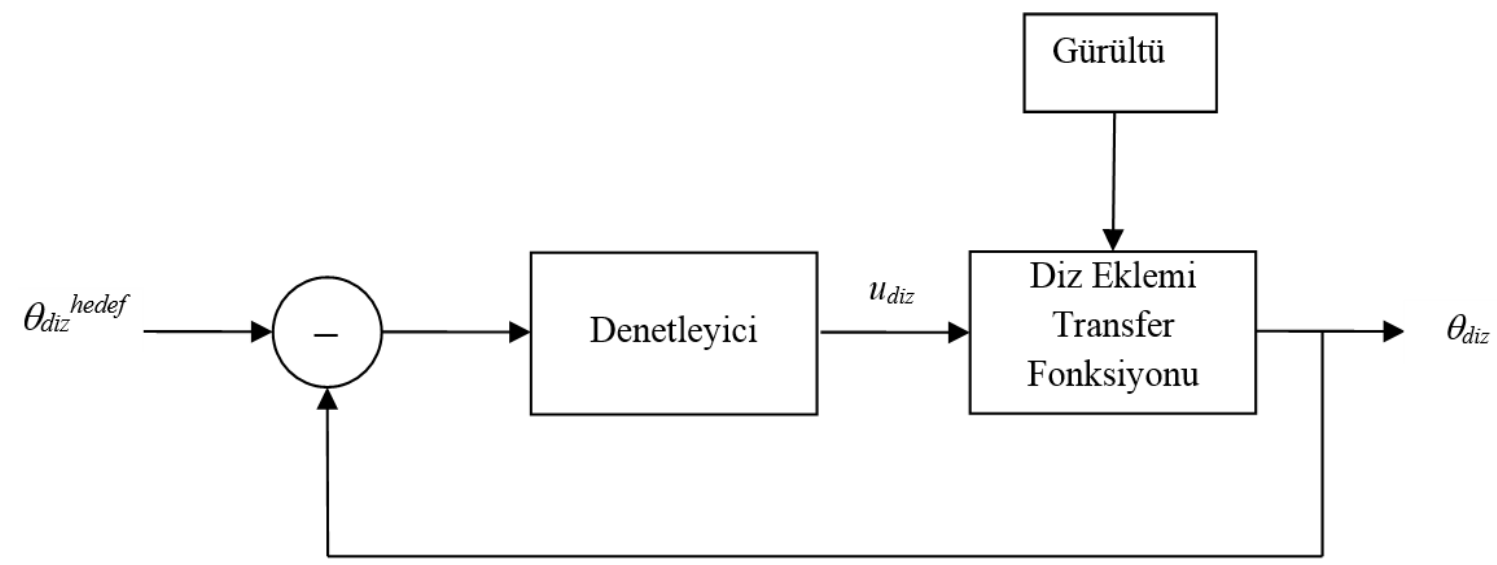

Şekil 4. OT denetleyicili diz eklemi sisteminin blok diyagramı (Block diagram of knee joint system with PD controller.)

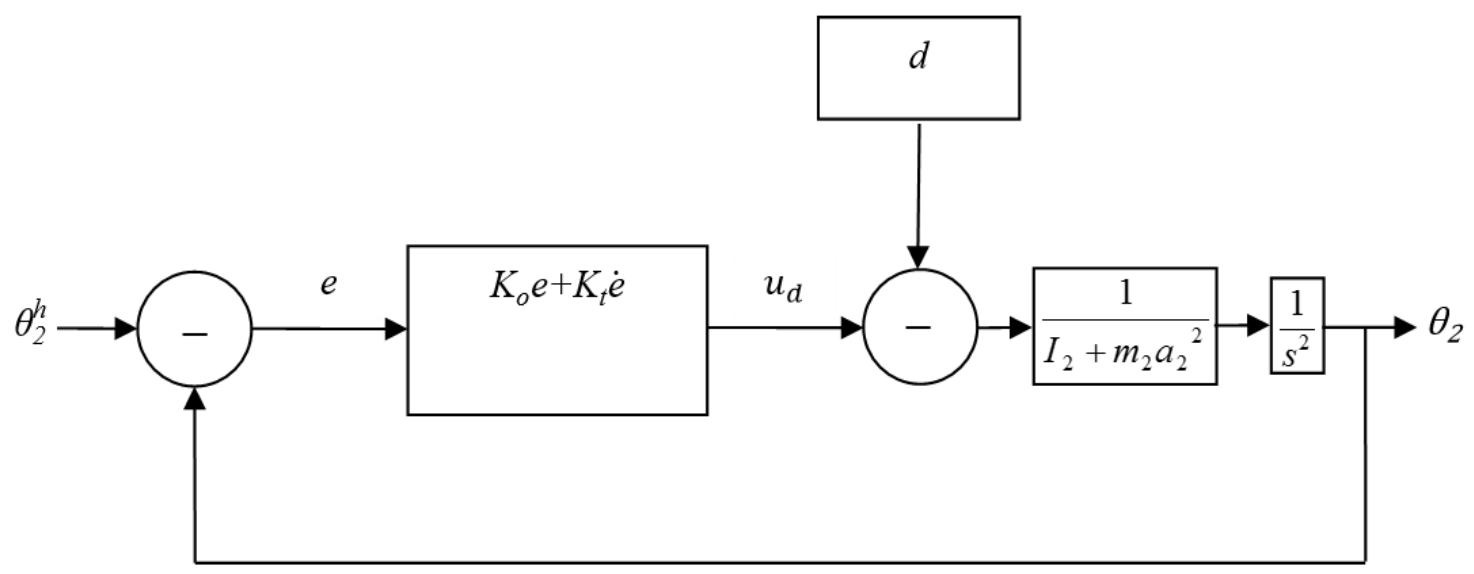

Şekil 5. Doğrusallaştırılmış diz eklemi transfer fonksiyonlu ve OT denetimli sistem. (System with linearized knee joint transfer function and PD control) 


$$
\begin{aligned}
& u_{d}=m_{2} l_{1} a_{2} \cos \left(\theta_{1}-\theta_{2}\right) \ddot{\theta}_{1}+\left(I_{2}+m_{2} a_{2}^{2}\right) \ddot{\theta}_{2}- \\
& m_{2} l_{1} a_{2} \sin \left(\theta_{1}-\theta_{2}\right) \dot{\theta}_{1}^{2}+ \\
& \left(m_{2} a_{2}\right)\left(\cos \left(\theta_{2}\right) \ddot{x}_{k}+\sin \left(\theta_{2}\right) \ddot{y}_{k}+\sin \left(\theta_{2}\right) g\right) \\
& u_{d}-\left(m_{2} l_{1} a_{2} \cos \left(\theta_{1}-\theta_{2}\right) \ddot{\theta}_{1}-m_{2} l_{1} a_{2} \sin \left(\theta_{1}-\theta_{2}\right) \dot{\theta}_{1}^{2}\right. \\
& \left.+\left(m_{2} a_{2}\right)\left(\cos \left(\theta_{2}\right) \ddot{x}_{k}+\sin \left(\theta_{2}\right) \ddot{y}_{k}+\sin \left(\theta_{2}\right) g\right)\right)= \\
& \left(I_{2}+m_{2} a_{2}^{2}\right) \ddot{\theta}_{2} \\
& d=m_{2} l_{1} a_{2} \cos \left(\theta_{1}-\theta_{2}\right) \ddot{\theta}_{1}-m_{2} l_{1} a_{2} \sin \left(\theta_{1}-\theta_{2}\right) \dot{\theta}_{1}^{2} \\
& +\left(m_{2} a_{2}\right)\left(\cos \left(\theta_{2}\right) \ddot{x}_{k}+\sin \left(\theta_{2}\right) \ddot{y}_{k}+\sin \left(\theta_{2}\right) g\right) \\
& \ddot{\theta}_{2}=\frac{u_{d}-d}{I_{2}+m_{2} a_{2}^{2}}
\end{aligned}
$$

\subsection{OT Denetleyici ve Kazançların Ayarlanması (PD Controller and Tuning Gains)}

Denetimsiz durum için geliştirilen ters çözüm, bu bölümde Şekil 5 'te gösterilen blok diyagram temel alınarak, OT denetimli sistemde kullanılmaktadır. EDP'nin kullanıldığı durumda kişinin kalçaya ait tork ve kinematik verilerinin bilindiği ancak hedef diz açısına ulaşmak için diz ekleminde oluşması gereken torkun bilinmediği varsayılmaktadır.

Şekil 5'te gösterilen diyagrama göre sistemin her bir örnekleme anı için dize uygulayacağ ekleminin bir önceki örnekte elde edilen diz açısı $\theta_{2}$ 'nin, hedef diz açısı $\theta_{2}^{h}$ 'den çıkarılmasıyla elde edilen hata $e$ ile oransal kazanç $K_{o}^{\prime}$ 'nun çarpımının ve hatanın türevi $\dot{e}$ ile $K_{t}$ türevsel kazancın çarpımının toplanması ile hesaplanmaktadır. Kalçaya ait verilerin bilindiği durumda, OT denetleyicisi ile diz eklemine uygulanan torka karşılık diz ekleminin alacağı açı, ters çözümle hesaplamaktadır. Bunun için (20) ile gösterilen denklem, ode45 çözücüsü için birinci dereceden diferansiyel denklem olarak düzenlenmelidir. Ode45'in bulması gereken bilinmeyenler (24), bu değişkenlere göre düzenlenen birinci dereceden diferansiyel denklemler ise (25) ve (26) ile gösterilmektedir.

$x(1)=\dot{\theta}_{2}, x(2)=\theta_{2}$

$d x 1=\left(u_{d}-0.2797 \cos \left(\theta_{1}-x(2)\right) \ddot{\theta}_{1}+\right.$

$0.2797 \sin \left(\theta_{1}-x(2)\right) \dot{\theta}_{1}^{2}-0.8908\left(\cos (x(2)) \ddot{x}_{k}+\right.$

$\left.\left.\sin (x(2)) \ddot{y}_{k}+\sin (x(2)) g\right)\right) / 0.2864$

$d x 2=x(1)$

İki eklem açısının bir arada hesaplandığı ters çözümde olduğu gibi (25) ve (26) ile gösterilen diferansiyel denklemlerin çözümü için kalçanın $x$ ve $y$ eksenlerindeki çizgisel ivmelerine ek olarak bulunması istenen her bir değişkenin ilk değerinin de bilinmesi gerekmektedir. İlk örnekleme anı için tanımlanan diz açısı ve diz açısal ivmesinin değerleri ile beraber, birinci ve ikinci örnekleme anına ait kalça verileri, ode45 çözücüsüne sağlanarak ikinci örnekleme anı için diz açısı ve diz açısal ivmesi hesaplanmaktadır. Bu döngü her bir gelecek diz örneği için tekrar edilmektedir. Döngünün her bir çevriminde, bir önceki çevrimde OT denetleyicisinin ürettiği diz torku, geçmiş diz açısı ve açısal hız değerleri, anlık ve geçmiş kalça açısı, açısal hızı ve ivmesi verileri ode45 çözücüsüne girilerek, ilgili anda bulunması istenen diz açısı ve açısal hızı hesaplanmaktadır.

Denetimli diz sisteminin çalışabilmesi için OT denetleyicinin uygun kazanç değerlerinin belirlenmesi gerekmektedir. Denetlenecek diz sisteminin transfer fonksiyonu bilindiğinden dolayı OT denetleyicinin kazanç değerleri, kök yer yöntemi ile hesaplanmaktadır. OT denetleyici ayrık zamanda çalıştığından dolayı ayrık zaman kök yer çözümlemesi yapılmalı ve bunun için de devamlı zamanda tanımlı diz transfer fonksiyonun, ayrik zaman karşılığı hesaplanmalıdır. Ode45 çözücüsüne, ayrık tork değerleri, doğrusal ara değerlendirme yapılarak sağlandığından devamlı ve ayrık zamanda yapılan çözümlerin uyuşması için diz transfer fonksiyonunun ayrı karşılığı, doğrusal ara değerlendirme yapan birinci dereceden tutucu (first order hold) kullanılarak MATLAB ile hesaplanmıştır. Diz protez sisteminin devamlı zamandaki transfer fonksiyonu ve Winter'ın verilerini topladığı örnekleme zamanı $\mathrm{T}=1 / 69 \mathrm{sn}$ için bu fonksiyonun ayrık zamandaki karşılığı (27) ile gösterilmektedir. OT denetleyicinin geri yönde fark (backward difference) yaklaştırması ile elde edilen $z$ bölgesindeki karşılığ $\quad$ (28) eşitliğinde gösterilmektedir.

$$
\begin{aligned}
& H(s)=\frac{3.492}{s^{2}} \rightarrow H(z)=\frac{1.191^{-4}(z+3.73)(z+0.27)}{(z-1)^{2}} \\
& D(z)=K_{O}+\frac{K_{T}\left(1-z^{-1}\right)}{T}=\frac{K_{O} T+K_{T}}{T z}\left(z-\frac{K_{T}}{K_{O} T+K_{T}}\right)
\end{aligned}
$$

Açık döngü transfer fonksiyonu $D(z) H(z)$ ile kök yer çözümlemesi için denetleyicili sistemin adım girişe göstereceği geçici tepkinin hedeflenen aşma yüzdesi (AY) (percentage overshoot) ve yükselme zamanına (YZ) (rising time) göre kapalı döngü sistemin sahip olması gereken baskın kutuplar hesaplanmaktadır. Eşitlik (29) ile hedeflenen $\mathrm{AY}=\% 20$ için sönümleme oranı (damping ratio) $\zeta$ ve eşitlik (30) ile hedeflenen $\mathrm{YZ}=0,041 \mathrm{sn}$ için doğal frekans (natural frequency) $w_{d}$ hesaplanmaktadır. Eşitlik (31) ile ifade edilen $s$ bölgesindeki baskın kutbun konumu ve (32) ile de bu kutbun $z$ bölgesinde karşılık geldiği nokta belirlenmektedir. 


$$
\begin{aligned}
& \zeta=\sqrt{\frac{\left(\ln \frac{A Y}{100}\right)^{2}}{\pi^{2}+\left(\ln \frac{A Y}{100}\right)^{2}}} \\
& w_{d}=\left(1.76 \zeta^{3}-0.417 \zeta^{2}+1.039 \zeta+1\right) / Y Z \\
& k_{s 1,2}=-\zeta w_{d} \pm j w_{d} \sqrt{1-\zeta^{2}} \\
& z=e^{s T}
\end{aligned}
$$

Kök yer çözümlemesi sonucu elde edilen eğrinin üzerinde yer alacak olan baskın kutup, $|D(z) H(z)|=1$ ve $\angle D(z) H(z)=180^{\circ}$ eşitliklerine yerleştirildiğinde, kapalı döngü sistemin istenen baskın kutba sahip olması için OT denetleyicinin kazançlarının $K_{o}=314$ ve $K_{t}=8$ olması gerektiği hesaplanmıştır. Sonuçta elde edilen kapalı döngü sistem (33) eşitliğinde gösterilmektedir. İstenen adım giriş tepkisi özelliklerine göre belirlenen sistemin baskın kutupları (33) eşitliğinde görülebilmektedir.

$$
\begin{aligned}
& G(z)=\frac{D(z) H(z)}{1+D(z) H(z)}= \\
& \frac{0.096101(z+3.732)(z-0.6475)(z+0.2679)}{(z-0.102)(z-0.6918-\mathrm{j} 0.3624)(z-0.6918+\mathrm{j} 0.3624)}
\end{aligned}
$$

Doğrulatma amacıyla elde edilen sistemin adım giriş tepkisi Şekil 6'da gösterilmektedir. Şekil 6'da gösterilen adım giriş tepkisinin tepe noktasına göre hesaplanan $\mathrm{AY}=\% 41,8$, son değerin \%90'nına ulaşmak için geçen süre $Y Z=0,022$ sn olarak belirlenmiştir. Yapılan tasarım sonucu elde edilen adım giriş tepkisi özellikleri, başlangıçta seçilen adım tepkisi özelliklerinden farklıdır. Bunun sebebi $S$ bölgesinde gerçek eksenin ' 0 ' noktasında yer alan kutuplardır. $\mathrm{Bu}$ kutuplar belirlenen adım tepkisini özelliklerine göre hesaplanan kutbun baskın olmasını engellemektedir.

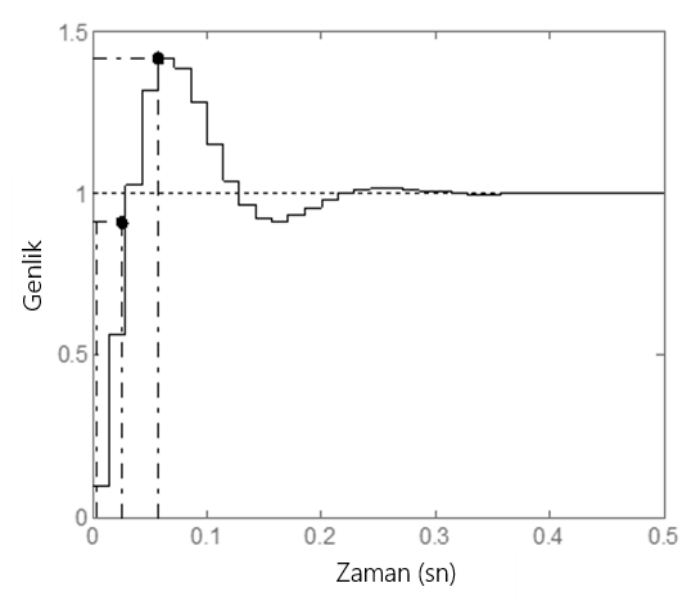

Şekil 6. $K_{o}=314, K_{t}=8$ kazançlarına sahip OT denetleyicili sistemin, adım giriş tepkisi (Step response of system with PD controller having gains $K_{p}=314, K_{d}=8$ )

\subsection{Diz Eklemi Denetimi (Knee Joint Control)}

Bir önceki bölümde kök yer çözümlemesi ile hesaplanan OT denetleyici kazançlarına sahip diz sisteminin geçici tepki özellikleri, tasarımın başlangıcında belirlenenlerden farklı olmasına karşın Şekil 5'teki denetimli diz sistemi için yeterlidir. Doğrusallaştırılmış diz sistemi için belirlenen OT kazanç değerleri Şekil 5'teki sisteme uygulanarak ve Winter'ın $6,2 \mathrm{~km} / \mathrm{sa}$ hızla yürüyen denekten ölçtüğü diz açısı, hedef açısı olarak tanımlanarak sistemin hedefi takip edebilme başarısı gözlemlenmiştir. Ters çözüm için gerekli kinematik değişkenler ve ilk değerler yine Winter'ın verilerinden sağlanmıştır. Elde edilen sonuç, Şekil 7'de gösterilmektedir. Hedef ve OT denetleyicili sistemin ürettiği diz açıları arasındaki farkın ortalama mutlak hatası $0,0192^{\circ}$ olarak ölçülmektedir. $\mathrm{Bu}$ sonuçlar 1şığında, OT denetim gibi temel bir denetim yönteminin bile EDP'de kullanılabileceğini görülmektedir.

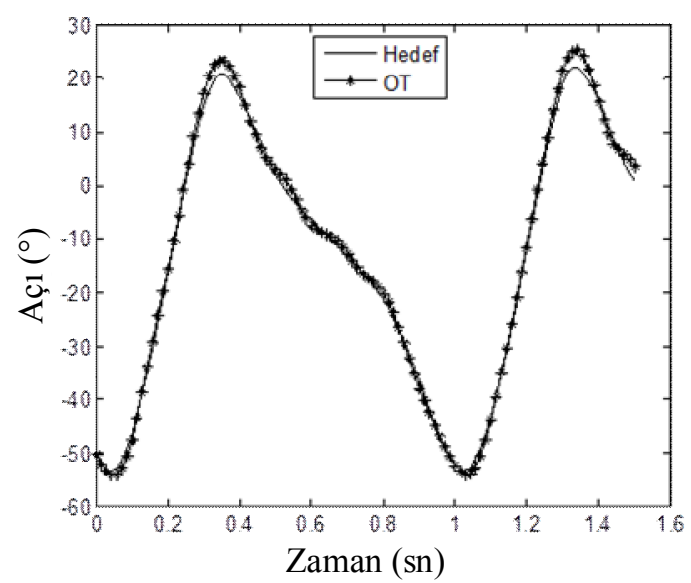

Şekil 7. $K_{o}=314, K_{t}=8$ kazançlarına sahip OT denetleyicili diz sisteminden elde edilen diz açısı $\left(^{*}\right)$ ve hedef diz açısı $(-)$, (Target $(-)$ and knee angle $\left({ }^{*}\right)$ achieved by knee system with PD controller having gains $\left.K_{p}=314, K_{d}=8\right)$.

\section{SONUÇLAR (CONCLUSIONS)}

$\mathrm{Bu}$ çalışmada bir EDP'nin temel bileşenlerinden biri olan denetim yönteminin geliştirilmesine yönelik bir benzetim ortamı oluşturulmuştur. Denetlenmek istenen yürüyüş hareketi, Kim ve Oh'nun önerdiği bacak modeli ve denklemler ile ifade edilmiştir. Bu denklemleri doğrulatmak için denklemler, iki eklemli düzlemsel robot kolu esas alınarak yeniden türetilmiştir. Denklemlerinin kullanılabilirliği ise Winter'ın ölçtüğü kinematik veriler ve hesapladığ kinetik verilerle sınanmıştır. Yapılan ileri çözüm sonucu, Kim ve Oh'nun yürüyüş denklemlerinden elde edilen torkun, Winter'ın hesapladığı torklar ile salınım evresinde uyuştuğu, duruş evresinde ise Winter'ın ölçtügü torkların belirgin derecede daha yüksek olduğu gözlenmiştir. Bunun sebebi, Kim ve Oh'nun yürüyüş denklemlerinin duruş evresinde oluşan yer tepki kuvvetini hesaba katmamasindan kaynaklanmaktadır. Dolayısıyla Kim ve Oh'nun 
denklemleri ile geliştirilecek bir EDP sadece yürüyüşün salınım evresinde kullanılabilecektir. Yürüyüş hareketinin eklemlerden uygulanan torkla iliş̧isini incelemek üzere Kim ve Oh'nun yürüyüş hareket denkleminin, kalça ve diz torklarına karşılık ürettiği eklem açıları sayısal olarak çözümlenmiştir. $\mathrm{Bu}$ ters çözüm, elektronik diz protezlerinde kullanılabilecek denetim yöntemlerinin uygulanmasına temel oluşturmaktadır. Elde edilen ters çözüm temel alınarak oluşturulan BTGO'da örnek bir denetim uygulaması yapmak amaciyla basit bir yapıya sahip olan ve temel denetim yöntemlerinden biri olan OT denetim yöntemi, protezli yürüyüş hareketine uygulanmıştır. Kalçanın sağlıklı ancak diz ekleminin protez olduğu bir durum için, tork ve diz açısı arasındaki yürüyüş denklemleri ile tanımlanan doğrusal olmayan ilişki doğrusallaştırılmış ve diz eklemi için bir transfer fonksiyonu oluşturulmuştur. Elde edilen transfer fonksiyonuna sahip diz sistemine, OT denetleyici uygulanarak bir kapalı döngü sistem oluşturulmuştur. Bu sistemin uygun görülen AY ve YZ'ye sahip adım tepkisi üretmesi için gereken baskın kutupları belirleyen OT kazanç değerleri kök yer yöntemi ile hesaplanmıştır. Ancak diz sisteminin $s$ bölgesinin gerçek ekseninin 0 noktasında iki kutbu olması, belirlenen kazanç değerlerine sahip sistemin başta belirlenen AY ve YZ'yi sağlayamamasına neden olmuştur. Buna rağmen elde edilen AY ve YZ değerleri, diz sistemi için yeterlidir. Belirlenen kazançlara sahip OT denetleyicili yürüyüş protezi sistemine, Winter'ın ölçtüğü diz açısı verilerini hedef değer olarak uygulandığında, sistemin ürettiği diz açısının hedef değeri takip edebildiği gözlemlenmiştir. Yapılan bu çalışmayla, EDP için OT ve diğer denetleyicilerin sinanabileceği, parametrelerinin kolaylıkla ayarlanabileceği bir benzetim tabanlı geliştirme ortamı oluşturulmuştur. Gelecek çalışmalarda bu tasarım ortamı kullanılarak, tanımlı bir hareketlendirici için OT denetleyicisinin yanı sıra daha gelişmiş denetim yöntemlerinin de incelenmesi amaçlanmaktadır.

\section{TEŞEKKÜR (ACKNOWLEDGEMENTS)}

$\mathrm{Bu}$ çalışma 112E316 no'lu Araştırma Projesi kapsamında, TÜBİTAK tarafindan desteklenmektedir.

\section{KAYNAKLAR (REFERENCES)}

1. Kay, H. W. ve Newman J. D., "Relative Incidences Of New Amputations: Statistical Comparisons Of 6,000 New Amputees", Orthotics and Prosthetics, Cilt 29, No 2, 3-16, 1975.

2. Flowers, W. C., "Use Of An Amputee-Computer Interactive Facility In Above-Knee Prosthesis Research", ACM Annual Conference/Annual Meeting, New York, 335-339, 1974.

3. Desdicioğlu, K., “Articulatio genu'nun morfolojik özellikleri”, Süleyman Demirel
Üniversitesi Tıp Fakültesi Dergisi, Cilt 15, No 1, 45-52, 2008.

4. Akdoğan, K. E., Pnömatik Ve Manyetoreolojik Silindirli Elektronik Diz Üstü Protezlerin Tasarımı Ve Geliştirilen Hareket İnceleme Sistemleri İle Karşılaştırılması, Doktora Tezi, Hacettepe Üniversitesi, Fen Bilimleri Enstitüsü, 2011.

5. Herr $H$. ve Wilkenfeld, A., "User-adaptive controlof a magnetorheological prosthetic knee", Industrial Robot: An International Journal, Cilt 30, No 1, 42-55, 2003.

6. Zlatnik, D., Steiner, B. ve Schweitzer, G., "Finite-state control of a trans-femoral (TF) prosthesis", IEEE Transactions on Control Systems Technology, Cilt 10, No 3, 408-420, 2002.

7. Wilkenfeld, A. J., Biologically Inspired Autoadaptive Control of a Knee Prosthesis, Doktora Tezi, Massachusetts Institute Of Technology, Department of Electrical Engineering and Computer Science, 2000.

8. Peeraer, L., Aeyels, B. ve Van der Perre, G., "Development of EMG-based mode and intent recognition algorithms for a computer-controlled above-knee prosthesis", Journal of Biomedical Engineering, Cilt 12, No 3, 178-182, 1990.

9. Carlson J. D., Matthis, W. ve Toscano, J. R., "Smart prosthetics based on magnetorheological fluids", 8th Annual Symposium on Smart Structures and Materials, Newport Beach, 308316, 2001.

10. Akdogan, K. E. ve Yilmaz, A., "Analysis of Direct Motion Measurement System for Design of Above Knee Prosthesis", International Conference on Virtual Environments, HumanComputer Interfaces and Measurement Systems (VECIMS 2010), Taranto, 56-59 2010.

11. Akdogan, K. E. ve Yilmaz, A., "Radyal Tabanlı Fonksiyon Ağları ile Yürüyüş Hareketinin Ölçümü ve Analitik Yöntemlerle Başarımının Karşılaştırılmasıı", Biyomedikal Mühendisliği Ulusal Toplantısı (BIYOMUT), İstanbul, 1-4, 2014.

12. Akdogan, K. E. ve Yilmaz, A., "Elektronik Diz Üstü Protez İçin Hareket Ölçüm Düzeneği Tasarımı", Biyomedikal Mühendisliği Ulusal Toplantısı (BIYOMUT), Antalya, 1-4, 2010.

13. Kim, J. H. ve Oh, J. H., "Development of an Above Knee Prosthesis using MR Damper and Leg Simulator", IEEE International Conference on Robotics \& Automation, Seoul, 3686-3691, 2001.

14. Winter D., Biomechanics and Motor Control of Human Movement, 3rd Edition, John Wiley \& Sons, New Jersey, A.B.D., 2005.

15. Spong, M. W., Hutchinson, S., ve Vidyasagar, M., Robot Modeling and Control, 1st Edition, John Wiley \& Sons, New Jersey, A.B.D., 2005. 
